\title{
Radioembolisation with Holmium-166 Polylactic Acid Microspheres: Distribution of Residual Activity and Flow Dynamics During Planning and Treatment Procedures
}

Martin Freesmeyer ( $\Delta$ martin.freesmeyer@med.uni-jena.de )

Clinic of Nuclear Medicine, Jena University Hospital https://orcid.org/0000-0002-6462-3851

Philipp Seifert

Universitatsklinikum Jena

Falk Gühne

Universitatsklinikum Jena

Christian Kühnel

Universitatsklinikum Jena

Robert Drescher

Universitatsklinikum Jena

Original research

Keywords: radioembolisation, holmium, SIRT, TARE, liver tumor

Posted Date: October 9th, 2020

DOI: https://doi.org/10.21203/rs.3.rs-88707/v1

License: (-) (i) This work is licensed under a Creative Commons Attribution 4.0 International License. Read

Full License 


\section{Abstract}

Purpose:

To evaluate the application dynamics and residual Ho-166 activity during and after transarterial radioembolisation planning and treatment procedures, and to assess the distribution and predilection sites of residual activity in the proprietary delivery set and microcatheter.

\section{Methods:}

16 planning (Holmium Scout Dose, HSD) and 12 therapeutic radioembolisation (RE) procedures were performed with poly-L-lactic acid (PLLA) microspheres loaded with Ho-166. The amount and distribution of residual activity was assessed by dose calibrator measurements and SPECT imaging. For 8 HSD and 5 RE procedures, the dynamic of the microsphere flow were assessed. For HSD procedures, different injection methods were evaluated.

Results:

The mean residual activities for HSD and RE procedures were $20.5+/-9.7 \%$ (range 7.2-44.1\%) and 4.8 +/-1.2\% (range 3.5-6.9\%), respectively. HSD residual activity could be decreased significantly with injections methods similar to RE procedures, from $31.2+/-9.6 \%$ to $17.7+/-6.9 \%$ and $15.0+/-6.0 \%(p=0.005)$. Main predilection sites of residual microspheres were the 3-way stopcock (HSD) and the outflow needle connector (RE). During $\mathrm{RE}$ procedures, $>80 \%$ of the injected activity is transferred during the first three injection cycles.

\section{Conclusion:}

After treatment procedures with PLLA microspheres, mean residual activity in the delivery set is reproducibly low and between reported values for glass and resin microspheres. The majority of microspheres is transferred to the patient during the second and third injection cycle. An estimated residual waste of $3 \%-4 \%$ may be included in the treatment activity calculation. For planning procedures, a modified injection technique should be used to avoid high residual activities.

\section{Introduction}

Transarterial radioembolisation is an interventional loco-regional treatment for primary and secondary liver malignancies [1]. Glass and resin microspheres loaded with Yttrium-90, and poly-L-lactic acid (PLLA) microspheres loaded with Holmium-166 are available. Potential advantages are the shorter half-life of Ho-166 $(26.8 \mathrm{~h})$ compared with Y-90 $(64.1 \mathrm{~h})$, its paramagnetic properties facilitating localisation and quantification by magnetic resonance (MR) imaging, and better visibility by SPECT due to its gamma radiation ( $81 \mathrm{keV}$ peak, abundance $6.7 \%)[2-4]$.

As for resin and glass microspheres, a proprietary administration device is provided by the manufacturer for PLLA microspheres. This "delivery set" should be used for planning and treatment procedures. For PLLA microspheres, an option is to perform the planning procedure (Holmium scout dose, HSD) with the same type of microspheres used for radioembolisation treatment (RE) instead of using Tc-99m macro-aggregated 
albumin (MAA) or similar radiopharmaceuticals, that are commonly used for glass and resin microsphere RE procedures [3]. The Ho-166 activity for a HSD procedure of the whole liver should not exceed $250 \mathrm{MBq}$ Ho166. The theoretical risk of extrahepatic tissue damage for this activity is low, which has been confirmed in 82 clinical procedures $[5,6]$. No adverse events related to extrahepatic depositions occurred after a median follow-up of 4 months [7].

Knowledge about handling specificities of the delivery set, the flow dynamics during microsphere injection, and potential problems which may impair complete administration of the therapeutic activity to the patient are of importance to the interventionalist. For resin and glass microspheres, it has been shown that the majority is transferred at the beginning of a procedure, with the activity flow decreasing nearly exponentially with each flushing cycle. Mean residual activities in the application devices for resin and glass of $4.0 \%$ (range $1.2-6.6 \%$ ) and $3.4 \%$ (range $0.9-8.8 \%$ ), respectively, have been reported [8,9]. Residual activities of up to $17 \%$ may occur $[10,11]$.

The aim of this study was to evaluate the handling of the PLLA microspheres delivery set, the microsphere flow dynamics during planning and treatment procedures, and to determine amount, variability and predilection sites of undelivered activity.

\section{Material And Methods}

All procedures were performed with Ho-166-loaded PLLA microspheres (QuiremSpheres, Terumo, Japan). Postprocedural measurements of residual activities and post- and periprocedural measurements of flow dynamics did not influence clinical decisions, conduct of the procedures and patient care. Institutional review board approval was not required.

Radioembolisation treatment of a whole liver with Holmium-containing microspheres was devised to be performed with $600 \mathrm{mg}$, equivalent to approximate 30 million PLLA microspheres. For a whole-liver HSD procedure, approx. 3 million PLLA microspheres should be used. This amount was shown to allow an accurate simulation of RE microsphere distribution and to contain an amount of holmium to be visible on MR imaging [12]. The microspheres are delivered in a vial (V-vial) in $2 \mathrm{ml}$ of a resuspension medium, containing Pluronic F-68 (Sigma-Aldrich Chemie B.V., The Netherlands) and phosphate buffer [13]. Calibration is done by the manufacturer so that the desired activity of Ho-166 in the V-vial is reached at the time of injection. For the HSD, two standard vials of $80 \mathrm{MBq}$ and $170 \mathrm{MBq}$ Ho-166 are delivered, but up to 3 vials with personalized activities not exceeding a total of $250 \mathrm{MBq}$ Ho-166 can be ordered (initial activities). For treatment, vials with personalized activities (prescribed activities) of $1 \mathrm{GBq}$ to $15 \mathrm{GBq}$ Ho-166 can be supplied [14].

PLLA microspheres have a density of $1.4 \mathrm{~g} / \mathrm{ml}$. The weight of 1 million microspheres is $20 \mathrm{mg}$, the Holmium content is $19-20 \%$ [3]. The specific activity of microspheres delivered for HSD ("QuiremScout") is lower than that used for RE procedures ("QuiremSpheres") due to different duration and intensity of neutron irradiation during production (4.2-4.7 MBq/mg and 11.6-15.3 MBq/mg, respectively, in this study). The mean number of microspheres containing $1 \mathrm{GBq} \mathrm{Ho}-166$ was $11.2+/-0.4$ million (range 10.6-11.9 million) for HSD and 3.8 +/-0.4 million (range 3.3-4.3 million) for RE. The number of microspheres containing a certain Ho-166 activity was calculated based on the specific activity given for each vial of PLLA microspheres. 
The delivery set consists of a tube line B (with syringe B) to inject $0.9 \%$ saline solution into the $V$-vial and to bring the microspheres into suspension, and a tube line $A$ (with syringe $A$ ) leading from the $V$-vial through a 3way stopcock, the patient line and the microcatheter to the patient (Fig. 1). Injections are done in a pulsed manner (approx. $0.1 \mathrm{ml}$ per push) with a maximum flow rate of $5 \mathrm{ml} / \mathrm{min}$ [15]. Microsphere administration is performed by injecting $0.9 \%$ saline solution into the $\mathrm{V}$-vial with syringe $\mathrm{A}$. Application of contrast medium and flushing of patient line/microcatheter with $0.9 \%$ saline solution is possible through the sidearm of the 3-way stopcock with syringe $B$. The inner volume of the system between the efferent needle and the tip of the microcatheter is $3.2 \mathrm{ml}$ (microsphere flow from V-vial to patient). For contrast media injection and flushing, the inner lumen between syringe $A$ and the tip of the microcatheter is $4.3 \mathrm{ml}$, and between the 3-way stopcock and the tip of the microcatheter is $2.4 \mathrm{ml}$. Setup of the delivery set is the same for HSD and RE procedures and was done strictly adhering to manufacturer recommendations [16]. Progreat $2.7 \mathrm{~F} / 130 \mathrm{~cm}$ microcatheters (Terumo, Japan; inner diameter $0.025 "$ ) were used.

\section{Holmium Scout dose (HSD) procedures}

16 HSD procedures with initial activities from 69.1 MBq to 173.7 MBq Ho-166 (mean 105.3 +/-41.7 MBq) were performed (Table 1). The mean number of microspheres was $1.18+/-0.49$ million (range $0.75-1.96$ million). In 8 cases, measurements were performed after clinical (in-vivo) treatment planning procedures. 8 procedures were performed solely for evaluation purposes (ex-vivo).

The method of injection of the HSD recommended by the manufacturer is to administer at least $20 \mathrm{ml}$ saline solution from syringe $B$, until the vial is visually empty. To compare residual activity and application dynamics, this method was compared with two modified RE injection methods :

- Method A, according to manufacturer specifications (5 procedures, 3 ex vivo):

6 cycles of $5 \mathrm{ml}(30 \mathrm{ml}$ in total) saline $0.9 \%$ from syringe $B$,

- Method B (4 procedures, 2 ex vivo):

4 cycles of $5 \mathrm{ml}$ saline $0.9 \%$ ( $20 \mathrm{ml}$ in total) from syringe B alternating with flushes of $2.5 \mathrm{ml}$ saline $0.9 \%$ from syringe $A$, followed by $10 \mathrm{ml}$ from syringe $B(2 \times 5 \mathrm{ml}$, to flush vial and lines),

- Method C (7 procedures, 3 ex vivo):

6 cycles of $5 \mathrm{ml}$ saline $0.9 \%$ (30 ml in total) from syringe B alternating with flushes of $2.5 \mathrm{ml}$ saline $0.9 \%$ from syringe $A$, followed by $10 \mathrm{ml}$ from syringe $B(2 \times 5 \mathrm{ml}$, to flush vial and lines).

To evaluate application dynamics during ex-vivo procedures, i.e. to assess the proportion of activity transferred with each injection cycle, for each cycle the microcatheter tip was placed in a $10 \mathrm{ml}$ collection tube for each cycle. Activity in the tubes was measured separately in a dose calibrator (ISOMED 2010, Nuvia Instruments, Germany), and the proportion per tube calculated in relation to the sum of all tubes.

\section{Radioembolisation (RE) procedures}

12 therapeutic, in-vivo RE procedures with prescribed activities from $993 \mathrm{MBq}$ to $4627 \mathrm{MBq}$ Ho-166 (mean $2900+/-1078 \mathrm{MBq}$ ) were performed (Table 3). The mean number of prescribed microspheres was 11.23 
+/-4.31 million (range 3.9-19.6 million). Injection was performed strictly adhering to manufacturer recommendations: 6 cycles of $2.5 \mathrm{ml}$ saline $0.9 \%$ from syringe $B$ alternating with $2.5 \mathrm{ml}$ contrast agent and $5 \mathrm{ml}$ saline $0.9 \%$ from syringe $A$ (at least 5 cycles are recommended), followed by $20 \mathrm{ml}$ from syringe $B$ ( $4 \times$ $5 \mathrm{ml}$, to flush vial and lines).

To enable continuous measurements of activity flow during a procedure, a shielded measurement chamber was constructed from a PLLA microspheres delivery shield, also containing a scintillator probe (Automess 6150AD-18) attached to a dose rate meter (DRM; 6150AD, Automess GmbH, Ladenburg, Germany)(Fig. 2). Readings in microsievert per hour $(\mu \mathrm{Sv} / \mathrm{h})$ were recorded in 1-second intervals. The sum of all dose rate readings per injection cycle divided by the sum of all cycles served as a surrogate to estimate the transferred activity per cycle (normalized to $60 \mathrm{~s}$ per cycle). The dynamic measurements described were carried out during five RE procedures (RE-08 to RE-12).

After HSD and RE procedures, to avoid redistribution of residual activity the clamp at the patient line was closed, and the tip of the microcatheter was sealed with an adhesive transparent film. Activity distribution in delivery sets with microcatheters and vials was visually assessed on SPECT/CT fusion images (Symbia S gamma camera, Siemens Healthineers, Germany; parameters: duration 4 min, 32 timeframes, 30 s per timeframe, 2 detectors, medium energy low penetration collimator, matrix $128 \times 128$, energy window $80 \mathrm{keV} / 15 \%$, and Biograph mCT40 CT scanner, Siemens Healthineers, Germany; parameters: slice thickness $1.5 \mathrm{~mm}$, tube voltage/current $80 \mathrm{kV} / 20 \mathrm{mAs}$ ). Imaging was performed after 14 of $16 \mathrm{HSD}$ and after all RE procedures, respectively. Activity accumulations and their locations were noted, foci with the highest intensity were identified. After imaging, residual activities in the vial and in the remainder of the delivery set (with microcatheter) were measured separately in a dose calibrator (ISOMED 2010, Nuvia Instruments, Germany). All activity measurements were normalized to the starting time of the administration.

\section{Statistical analysis}

For statistical evaluation, $\mathrm{p}$-values were calculated using the two-sided Mann-Whitney-U test for independent samples. ANOVA analyses were performed to evaluate variance between more than two groups. Pearson's coefficients calculations were carried out to evaluate correlations (SPSS Statistics, IBM, version 24).

\section{Results}

\section{HSD procedures}

No technical failures, e.g. line/catheter blockages or leakages, occurred during the procedures. The mean residual activity remaining in the delivery sets and V-vials was $20.5+/-9.7 \%$ (range $7.2-44.1 \%$ ) of the initial activity (Table 1). The mean number of residual microspheres was $0.25+/-0.18$ million (range $0.06-$ 0.63 million).

Using injection methods B or C, residual activities were significantly lower compared with method $A$, but still highly variable, from $7.2-23.8 \%$ (Table 2 , power of analysis: .338). With all methods of injection, residual activity in the V-vials was significantly lower than in the delivery set $(3.1+/-1.7 \mathrm{MBq}$, range 1.2-8.3 MBq and $19.3+/-14.5 \mathrm{MBq}$, range 3.8-50.2 MBq, respectively; $\mathrm{P}<.0001$ ). The high variability of residual activities was therefore caused by microspheres remaining in the delivery set. Mean residual activity in the $\mathrm{V}$-vials was 3.0 
$+/-1.1 \%$ (range $1.1-5.5 \%$ ) of the initial activity, in all cases located only (8/14 procedures, $57 \%$ ) or predominantly (6/14 procedures, $43 \%$ ) at the bottom (Fig. 3, insets). No significant difference was detected between methods $B$ and $C$ regarding relative residual activities (mean $17.7 \pm 6.9 \%$ and $15.0 \pm 6.0 \%$, respectively). Visual predilection sites of microsphere accumulation were the connector of the outflow needle $A$ at the $\mathrm{V}$-Vial, the microcatheter connector, the 3-way stopcock (junction between inflow and pivoting part) and the proximal end of the patient line close to the 3-way stopcock (Fig. 3a, 4). On SPECT imaging, highest intensities were visualized at the 3-way stopcock $(8 / 14$ procedures, $57 \%)$ and at the microsphere connector (microcatheter side of the luer lock, 4/14 procedures, 29\%). After the procedure with the highest residual activity of $44 \%$ (HSD-04), a large activity accumulation was located at the microcatheter connector, distributing the adjacent lines (Fig. 5). No backflow of activity into the inflow needle A or into the sidearm of the 3-way stopcock was identified.

Dynamic evaluations were performed during the six ex-vivo procedures and showed that with method $A$, the majority of the microspheres were transferred during the second half of the procedure, at injection cycles 4 and 5 (mean $24 \%$, range $10-36 \%$ and mean $32 \%$, range $28-37 \%$, respectively)(Fig. 6). Using injection methods $\mathrm{B} / \mathrm{C}$, the majority of the microspheres were transferred during injection cycles 2 and 3 (mean $50 \%$, range $39-65 \%$ and mean $23 \%$, range $8-42 \%$, respectively). Injection cycles $5 / 6$ (method $B$ ) or $7 / 8$ (method C), with a mean transferred activity during these steps of $0.6 \%$, range $0.0-2.0 \%$ ) therefore represent real flushing steps, aimed at emptying the delivery set.

After all in-vivo procedures, SPECT/CT imaging was performed and deemed sufficient for RE planning.

\section{RE procedures}

No technical failures occurred during the procedures. The mean relative residual activity remaining in the delivery sets and V-vials was $4.8+/-1.2 \%$ (range $3.5-6.9 \%$ ) of the prescribed activity (Table 3 ). The mean number of residual microspheres was 0.50 million $+/ 0.15$ million (range $0.27-0.77$ million). A moderate negative correlation between relative residual activity and prescribed activity was evident $(r=-6754 ; P=.016)$. Absolute residual activities showed a strong positive correlation to prescribed activities $(r=.8 ; P<.01)$. The lowest absolute residual activity was measured after the procedure with the lowest prescribed activity (RE-09, Table 3$)$, representing the highest relative residual activity $(6.9 \%)$.

Residual activity in the V-vials was significantly lower than in the delivery sets $(39.8+/-29.1 \mathrm{MBq}$, range 7.7119.9 MBq; and 90.1 +/-38.6 MBq, range 38.6-170.9 MBq; $\mathrm{P}=.002$ ). Mean residual activity in the $\mathrm{V}$-vials was $1.5+/-0.9 \%$ (range $0.2-3.2 \%$ ) of the prescribed activity. In the imaged V-vials, this activity was located at the bottom ( $4 / 12$ procedures, $33 \%)$, predominantly at the bottom (6/12 procedures, $50 \%$, including procedure RE07 with the highest residual V-vial activity), or predominantly at the top (2/12 procedures, $17 \%)$.

Contribution of V-vials and delivery sets towards the total residual activity was highly variable: After the two procedures with the lowest total residual activity of 3.5\% (RE-03 and RE-10), proportion of these activities in the V-vials were $0.3 \%$ and $1.5 \%$. After the two procedures with highest total residual activities of $6.7 \%$ and $6.9 \%$ (RE-08 and RE-09), proportions in the V-vials were $2.9 \%$ and $1.7 \%$. 
Visual predilection sites of microsphere accumulation after all procedures were the same as after HSD procedures: connector of the outflow needle $\mathrm{A}$ at the $\mathrm{V}$-Vial, microcatheter connector (microcatheter side of the luer lock), 3-way stopcock, and proximal end of the patient line (Fig. 3b, 4). Focal spots with the highest intensities were visualized at the needle connector ( $9 / 12$ procedures, $75 \%)$ and in the $\mathrm{V}$-vial $(3 / 12$ procedures, $25 \%$, Table 3). In one case, an additional focus of residual activity was seen in the line between needle $A$ and 3-way stopcock (procedure RE-12). No backflow of activity into the inflow needle (from syringe $B$ ) or into the sidearm of the 3-way stopcock was identified.

Dynamic evaluations showed that the majority of the microspheres were transferred through the patient line at the beginning of the procedure (Table 4). After the first two injection cycles, more than $60 \%$ (range $61-$ $71 \%$ ), after the first three injection cycles, more than $80 \%$ (range $85-92 \%$ ) were transferred. Less than $3 \%$ were transferred during the sixth injection cycle and the final flushing combined (range 1.6-2.3\%).

\section{Technical considerations}

The PLLA microspheres delivery set is similar to the resin microspheres administration device: Injection is done from two syringes (microsphere administration and flushing/contrast media application), between which can be chosen by a 3-way stopcock, operated by a dial (Fig. 1). In contrast, the construction of the glass microspheres administration device is simpler, with only one syringe and no 3-way stopcock, because no intermittent flushing or contrast application is done during the procedure [9]. It was noted that after complete priming of the delivery sets with $0.9 \%$ saline solution, in the majority of cases air was flowing back into tube line $A$ as long as the dial was set to the prime position. This can be avoided by setting the dial from prime to contrast position while injecting with syringe $A$, then closing the clip at the patient line and setting the dial to close position (counter-clockwise) while pushing syringe A. Residual air bubbles tended to accumulate at the sidearm of the 3-way stopcock (blue) and at the tube line A tee connector (Fig. 1). Priming should be done slowly to prevent the formation of small air bubbles in the lines which are difficult to flush out. During the procedure, arterial flow is visualized intermittently by injecting contrast media, allowing the interventionalist to immediately adapt the injection rate in case of flow reduction or stasis.

\section{Discussion}

In previous studies evaluating RE with Ho-166 and introducing it into clinical practice, different injection methods and delivery sets were used. In an early feasibility study, microspheres were injected through a custom-made delivery set by injecting $15-20 \mathrm{ml}$ of saline solution [17]. At that time, no proprietary delivery set for PLLA microspheres was available. In a later animal study and in the HEPAR I dose escalation study, pulsatile injection was done with a contrast media/saline mixture to provide constant control over the microsphere flow $[18,12,19]$. Currently, the manufacturer recommends to flush PLLA microspheres from the vial with saline solution, with intermittent injection of contrast media to check the arterial flow, through a proprietary delivery set $[16,14]$.

In a study comparing the prediction of lung shunting by HSD and MAA, the same injection method as in the HEPAR I dose escalation study with a mixture of contrast media/saline was used, but no residual activity values are reported [6]. In the HSD safety study a mean residual activity of $8.7 \%$ was detected (prescribed activities 105-326 MBq Ho-166; administered activities 103-313 MBq Ho-166) [7]. In the mentioned studies, 
injections were performed with 2.4 F or 2.7 F microcatheters (Progreat, Terumo, Japan) [4]. Compared with RE, a simplified injection method for HSD procedures is now recommended, during which injection is done solely through the V-vial [15]. Surprisingly, after the first two HSD procedures performed with this technique in our institution, we detected very high residual activities of $17.3 \%$ and $31.2 \%$ in the delivery sets (HSD-01 and HSD02, Table 1). Further ex-vivo evaluations performed with the simplified injection method showed even higher residual activities of up to $44.1 \%$ (HSD-04). In the clinical, in-vivo cases in our study, it was still possible to see in which liver segments activity distribution occurred, but absolute quantification would be impaired. Relevant proportions of the microspheres were transferred to the patient during later injection cycles, at a point when the interventionalist may assume that he is just flushing lines and catheters before removal (Fig. 6, method A). With a change of the injection method to resemble the method used for RE procedures, residual activity in the delivery sets could be decreased significantly. An increase of the number of injection cycles from 4 to 6 (injection methods $\mathrm{B}$ to $\mathrm{C}$ ) reduced lead to minor further reduction (Table 2). Application dynamics was improved: The majority of microspheres was transferred during the first injection cycles (mean $50 \%$ and $23 \%$ during cycles 2 and 3 , respectively), and low activity was transferred during flushing at the end of the procedure (Fig. 6, methods B/C).

After RE procedures with PLLA microspheres evaluated in this study, using the injection method proposed by the manufacturer, a mean relative residual activity of $4.8 \%$ was detected in the delivery sets, ranging from $3.5-6.9 \%$. These findings are similar to those measured after procedures with resin (4.0\%, range 1.2-6.6\%) and glass microspheres (3.4\%, range 0.9-8.8\%). Compared with resin and glass, with PLLA microspheres relative residual activity was less variable [8]. In the HEPAR I study, a mean residual activity of $6.1 \%$ was recorded, but the complete injection process was done with a mixture of contrast media/saline [19]. That study also found that relative residual activity was lower in the groups receiving the highest prescribed activities. In the phase II study evaluating Ho-166 microspheres for treatment of liver metastases in 38 patients, a median of $96 \%$ (range $41-99 \%$ ) of the prescribed activity was injected. The injection method is not described in detail. It is mentioned that in some cases, stasis occurred or infusion was stopped because of pain [20].

Our measurements revealed a moderate negative correlation between initial/prescribed activity and relative residual activity, but no definite upper limit (saturation) of absolute residual activity could be identified. Taking the number of microspheres instead of the Ho-166 activity into account, about 10-fold more microspheres were used for RE than for HSD procedures (mean: 11.23 million and 1.18 million, respectively), but the number of residual microspheres was only 2 -fold higher (mean: 0.50 million and 0.25 million). This suggests that a limited number of microspheres gets stuck at the predilection sites, which represent irregularities at the inner surface of lines and catheters, but the high variability in the proportion of residual microspheres does not allow a prospective estimation, particularly for HSD procedures.

Evaluation of infusion dynamics showed that in all RE procedures, more than $80 \%$ of the activity is transferred to the patient during the first three injection cycles (Fig. 7). This dynamic profile is similar to resin microsphere and slower than glass microsphere injection. With neither microsphere type, treatment at more than one catheter position from one V-vial should be done, because microsphere transfer and distribution would not be predictable. 
Predilection sites in the delivery sets for residual microspheres were the same for HSD and RE procedures. After HSD and RE procedures, the 3-way stopcock and the needle A connector were the sites of the most intense activity accumulations, respectively (Fig. 3). Apparent microsphere accumulations at the microcatheter connector (Fig. 3b) were reduced by positioning it at a downward angle instead of horizontally, while the length of the patient line remained horizontally. The accumulations of microspheres in the proximal part of the patient line (Fig. 3d) were seen to decrease when injecting with syringe A through the sidearm of the stopcock. As with glass microspheres, after all procedures in this study variable amounts of activity remained at the microcatheter connector, emphasizing the recommendation that delivery set and catheter should be disposed of without disconnection [9]. Treatment from different vascular positions with the same microcatheter should be avoided.

All predilection sites of microsphere accumulation correspond to irregularities/steps at the inner surface of lines and catheters, at the luer-lock connection of two parts or at the rotating part of the 3-way stopcock. In a delivery set which is not assembled from different parts, but manufactured as one system avoiding these irregularities, low residual activities can be expected. A dedicated delivery set only for HSD procedures may be simpler, without the 3-way stopcock and an optimized luer-lock connector for the microcatheter.

At the beginning of injecting into the V-Vial, it sometimes took several pushes to bring the microspheres into suspension, due to their tendency to stick together at the bottom of the vial. The time period between the final production step and the procedure may be 1-3 days, during which the microspheres are not resuspended. As for glass microspheres, which are delivered in patient-specific doses, we recommend to swivel and tilt the $\mathrm{V}$ vial several times while it remains in the lead/acrylic container used for delivery. This problem does not arise with resin microspheres, since the patient-specific dose is prepared on-site usually on treatment day. The microspheres do not have time to agglutinate on the bottom of the vial. In this study, there was no evidence of adhesion of microspheres to the rubber septa after swivelling as a possible reason for abnormally high residual activities in V-vials. The bevelled aspects of the needles, which have a higher diameter than those used in resin or glass microsphere administration devices $(1.2 \mathrm{~mm}, 0.8 \mathrm{~mm}$ and $0.9 \mathrm{~mm}$, respectively), should face away from the inner $V$-vial surface to facilitate unhindered microsphere outflow.

Limitations of the study include the small number of procedures, particularly regarding HSD procedures. Not all dose sizes could be tested with all injection methods; it was tried to reach improvements parallel to clinical routine. Only one type of microcatheter was used for all procedures. Different types may impact residual activity at the microcatheter connector. All procedures were performed by the same physician in a standardized manner. Influences by different operators performing the manual injection could not be evaluated. It can be hypothesized that this variability is higher for HSD than for RE procedures, because due the lower number of microspheres used in HSD procedures it may be vulnerable to variations in injection speed and manner (e.g. continuous or pulsatile).

\section{Conclusion}

The proprietary delivery set for PLLA microspheres is technically feasible for clinical use. Completeness and reproducibility of microsphere transfer to the patient during HSD procedures may be unfavourable when using the simplified injection method. An injection technique resembling the method used for RE procedures should 
be used. For RE procedures, the standard injection method leads to comparably low residual activities in the delivery sets. Inclusion of an estimated residual waste of $3-4 \%$ in the calculation of the prescribed activity appears to be feasible to increase treatment accuracy, and to avoid undertreatment. Taking variability into account, the amount of activity injected into the patient and the resulting tumor dose may be up to $10 \%$ lower than calculated. As with delivery sets for resin and glass microspheres, constructional changes of the PLLA microspheres delivery set, focusing on the needle/microcatheter connectors and 3-way stopcock, would help to reduce residual activities and ensure consistent application of the prescribed activity to the patient. Different delivery sets for HSD and RE procedures may be considered.

\section{List Of Abbreviations}

CT computed tomography

DRM dose rate meter

HSD Holmium Scout Dose

MAA macro-aggregated albumin

MR magnetic resonance

PLLA poly-L-lactic acid

$\mathrm{RE}$ radioembolisation

SPECT single photon emission computed tomography

TARE transarterial radioembolisation

\section{Declarations}

Funding:

This research was funded from the regular budget of the Jena University Hospital.

Conflicts of interest/Competing interests:

None.

Ethics approval:

Ethics approval was not necessary due to the laboratory nature of the research. Measurement of residual activity after radioembolisation procedures is clinical routine.

Consent to participate/consent for publication:

Not applicable. 
Availability of data and material:

Data and materials support their published claims and comply with field standards.

Code availability:

Not applicable.

Authors' contributions:

All authors contributed to the study conception and design. Material preparation, data collection and analysis were performed by Robert Drescher, Falk Gühne, Philipp Seifert and Christian Kühnel. The first draft of the manuscript was written by Martin Freesmeyer and Robert Drescher. All authors commented on previous versions of the manuscript. All authors read and approved the final manuscript.

\section{References}

1. Bester L, Meteling B, Boshell D, Chua TC, Morris DL. Transarterial chemoembolisation and radioembolisation for the treatment of primary liver cancer and secondary liver cancer: a review of the literature. J Med Imaging Radiat Oncol. 2014;58(3):341-52. doi:10.1111/1754-9485.12163.

2. Klaassen NJM, Arntz MJ, Gil Arranja A, Roosen J, Nijsen JFW. The various therapeutic applications of the medical isotope holmium-166: a narrative review. EJNMMI Radiopharm Chem. 2019;4(1):19. doi:10.1186/s41181-019-0066-3.

3. Reinders MTM, Smits MLJ, van Roekel C, Braat A. Holmium-166 Microsphere Radioembolization of Hepatic Malignancies. Semin Nucl Med. 2019;49(3):237-43. doi:10.1053/j.semnuclmed.2019.01.008.

4. Smits MLJ, Dassen MG, Prince JF, Braat A, Beijst C, Bruijnen RCG et al. The superior predictive value of (166)Ho-scout compared with (99m)Tc-macroaggregated albumin prior to (166)Ho-microspheres radioembolization in patients with liver metastases. Eur J Nucl Med Mol Imaging. 2019. doi:10.1007/s00259-019-04460-y.

5. Prince JF, van Rooij R, Bol GH, de Jong HW, van den Bosch MA, Lam MG. Safety of a Scout Dose Preceding Hepatic Radioembolization with 166Ho Microspheres. J Nucl Med. 2015;56(6):817-23. doi:10.2967/jnumed.115.155564.

6. Elschot M, Nijsen JF, Lam MG, Smits ML, Prince JF, Viergever MA et al. ((9)(9)m)Tc-MAA overestimates the absorbed dose to the lungs in radioembolization: a quantitative evaluation in patients treated with (1) (6)(6)Ho-microspheres. Eur J Nucl Med Mol Imaging. 2014;41(10):1965-75. doi:10.1007/s00259-0142784-9.

7. Braat A, Prince JF, van Rooij R, Bruijnen RCG, van den Bosch M, Lam M. Safety analysis of holmium-166 microsphere scout dose imaging during radioembolisation work-up: A cohort study. Eur Radiol. 2018;28(3):920-8. doi:10.1007/s00330-017-4998-2.

8. Drescher R, Gühne F, Seifert P, Kühnel C, Freesmeyer M. Ex Vivo Evaluation of Residual Activity and Infusion Dynamics in a Commercially Available Yttrium-90 Resin Microsphere Administration System. J Vasc Interv Radiol. 2019;30:1504-11. 
9. Drescher R, Seifert P, Gühne F, Kühnel C, Aschenbach R, Freesmeyer M. Transarterial Radioembolization with Yttrium-90 Glass Microspheres: Distribution of Residual Activity and Flow Dynamics during Administration. J Vasc Interv Radiol. 2020;31(9):1467-74. doi:10.1016/j.jvir.2020.02.002.

10. Piana PM, Bar V, Doyle L, Anne R, Sato T, Eschelman DJ et al. Early arterial stasis during resin-based yttrium-90 radioembolization: incidence and preliminary outcomes. HPB (Oxford). 2014;16(4):336-41. doi:10.1111/hpb.12135.

11. Ahmadzadehfar H, Meyer C, Pieper CC, Bundschuh R, Muckle M, Gartner F et al. Evaluation of the delivered activity of yttrium-90 resin microspheres using sterile water and $5 \%$ glucose during administration. EJNMMI Res. 2015;5(1):54. doi:10.1186/s13550-015-0133-z.

12. Vente MA, de Wit TC, van den Bosch MA, Bult W, Seevinck PR, Zonnenberg BA et al. Holmium-166 poly(Llactic acid) microsphere radioembolisation of the liver: technical aspects studied in a large animal model. Eur Radiol. 2010;20(4):862-9. doi:10.1007/s00330-009-1613-1.

13. Bakker RC, de Roos R, Ververs FFT, Lam M, van der Lee MK, Zonnenberg BA et al. Blood and urine analyses after radioembolization of liver malignancies with [(166)Ho]Ho-acetylacetonate-poly(I-lactic acid) microspheres. Nucl Med Biol. 2019;71:11-8. doi:10.1016/j.nucmedbio.2019.03.001.

14. Quirem Medical B.V. Instructions for use Ho-166-PLLA microspheres, version LS-1101-10. 2017.

15. Quirem Medical B.V. QuiremSpheres administration procedure quick guide, version MAN-1101-18-00. 2018.

16. Quirem Medical B.V. Instructions for use QuiremSpheres customer kit (QS-C001) and delivery set (QSD001), version MAN-1101-17-02, Rev. 02. 2017.

17. Vente MA, Nijsen JF, de Wit TC, Seppenwoolde JH, Krijger GC, Seevinck PR et al. Clinical effects of transcatheter hepatic arterial embolization with holmium-166 poly(L-lactic acid) microspheres in healthy pigs. Eur J Nucl Med Mol Imaging. 2008;35(7):1259-71. doi:10.1007/s00259-008-0747-8.

18. Smits ML, Nijsen JF, van den Bosch MA, Lam MG, Vente MA, Huijbregts JE et al. Holmium-166 radioembolization for the treatment of patients with liver metastases: design of the phase I HEPAR trial. J Exp Clin Cancer Res. 2010;29:70. doi:10.1186/1756-9966-29-70.

19. Smits ML, Nijsen JF, van den Bosch MA, Lam MG, Vente MA, Mali WP et al. Holmium-166 radioembolisation in patients with unresectable, chemorefractory liver metastases (HEPAR trial): a phase 1, dose-escalation study. Lancet Oncol. 2012;13(10):1025-34. doi:10.1016/S1470-2045(12)70334-0.

20. Prince JF, van den Bosch M, Nijsen JFW, Smits MLJ, van den Hoven AF, Nikolakopoulos S et al. Efficacy of Radioembolization with (166)Ho-Microspheres in Salvage Patients with Liver Metastases: A Phase 2 Study. J Nucl Med. 2018;59(4):582-8. doi:10.2967/jnumed.117.197194.

\section{Tables}


Table 1

Holmium scout dose (HSD): Procedure characteristics

\begin{tabular}{|c|c|c|c|c|c|c|c|c|}
\hline \multirow{2}{*}{$\begin{array}{l}\text { Procedures } \\
\text { (chrono- } \\
\text { logical) }\end{array}$} & \multirow{2}{*}{$\begin{array}{l}\text { Initial } \\
\text { activities } \\
\text { V-vial } \\
\text { (MBq) }\end{array}$} & \multirow{2}{*}{$\begin{array}{l}\begin{array}{l}\text { No. of } \\
\text { micro- } \\
\text { spheres }\end{array} \\
\text { V-vial } \\
\text { (millions) }\end{array}$} & \multicolumn{4}{|c|}{ Residual activities } & \multirow{2}{*}{$\begin{array}{l}\text { Method } \\
\text { of } \\
\text { injection }\end{array}$} & \multirow{2}{*}{$\begin{array}{l}\text { Localization } \\
\text { of high activity } \\
\text { accumulations }\end{array}$} \\
\hline & & & $\begin{array}{l}\text { V-vial } \\
(\mathrm{MBq})\end{array}$ & $\begin{array}{l}\text { Delivery } \\
\text { set } \\
\text { (MBq) }\end{array}$ & $\begin{array}{l}\text { Total } \\
(\mathrm{MBq})\end{array}$ & $\begin{array}{l}\text { Total } \\
\text { (\%) }\end{array}$ & & \\
\hline HSD-01 & 73.7 & 0.9 & 2.1 & 10.7 & 12.8 & 17.3 & A & - \\
\hline HSD-02 & 160 & 1.9 & 1.7 & 48.2 & 49.9 & 31.2 & A & - \\
\hline HSD-03* & 161.1 & 1.9 & 3.7 & 50.2 & 54.0 & 33.5 & A & $\begin{array}{l}\text { 3-way } \\
\text { stopcock }\end{array}$ \\
\hline HSD-04* & 84.9 & 1.0 & 2.5 & 34.9 & 37.4 & 44.1 & A & $\begin{array}{l}\text { microcatheter } \\
\text { connector }\end{array}$ \\
\hline HSD-05* & 173.7 & 1.9 & 5.3 & 16.9 & 22.2 & 12.8 & B & $\begin{array}{l}\text { 3-way } \\
\text { stopcock }\end{array}$ \\
\hline HSD-06* & 74.4 & 0.8 & 2.7 & 7.0 & 9.7 & 13.1 & B & $\begin{array}{l}\text { 3-way } \\
\text { stopcock, V- } \\
\text { vial }\end{array}$ \\
\hline HSD-07 & 168.5 & 2.0 & 4.5 & 35.7 & 40.2 & 23.8 & B & $\begin{array}{l}\text { 3-way } \\
\text { stopcock }\end{array}$ \\
\hline HSD-08 & 74.4 & 0.9 & 2.9 & 10.0 & 13.0 & 17.5 & B & $\begin{array}{l}\text { 3-way } \\
\text { stopcock }\end{array}$ \\
\hline HSD-09* & 83.1 & 0.9 & 1.8 & 6.9 & 8.7 & 10.5 & C & $\begin{array}{l}\text { 3-way } \\
\text { stopcock, } \\
\text { microcatheter } \\
\text { connector }\end{array}$ \\
\hline HSD-10* & 69.1 & 0.8 & 3.8 & 3.8 & 7.6 & 10.9 & C & $\begin{array}{l}\text { V-vial, 3-way } \\
\text { stopcock }\end{array}$ \\
\hline HSD-11* & 72.9 & 0.8 & 1.2 & 4.1 & 5.3 & 7.2 & C & $\begin{array}{l}\text { needle A } \\
\text { connector, 3- } \\
\text { way stopcock }\end{array}$ \\
\hline HSD-12 & 72.5 & 0.8 & 1.7 & 15.1 & 16.8 & 23.2 & C & $\begin{array}{l}\text { microcatheter } \\
\text { connector,3- } \\
\text { way stopcock }\end{array}$ \\
\hline HSD-13 & 83.6 & 0.9 & 2.0 & 16.4 & 18.4 & 22.1 & C & $\begin{array}{l}\text { 3-way } \\
\text { stopcock, } \\
\text { microcatheter } \\
\text { connector }\end{array}$ \\
\hline HSD-14* & 75.8 & 0.8 & 1.7 & 20.9 & 22.6 & 29.8 & A & $\begin{array}{l}\text { microcatheter } \\
\text { connector, 3- } \\
\text { way stopcock }\end{array}$ \\
\hline
\end{tabular}




\begin{tabular}{|c|c|c|c|c|c|c|c|c|}
\hline \multirow{2}{*}{$\begin{array}{l}\text { Procedures } \\
\text { (chrono- } \\
\text { logical) }\end{array}$} & \multirow{2}{*}{$\begin{array}{l}\text { Initial } \\
\text { activities }\end{array}$} & \multirow{2}{*}{$\begin{array}{l}\begin{array}{l}\text { No. of } \\
\text { micro- } \\
\text { spheres }\end{array} \\
0.9\end{array}$} & \multicolumn{4}{|c|}{ Residual activities } & \multirow{2}{*}{$\begin{array}{l}\text { Method } \\
\text { of } \\
\text { injection }\end{array}$} & \multirow{2}{*}{ 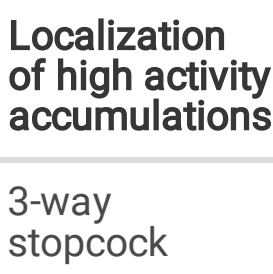 } \\
\hline & & & 3.6 & 11.1 & 14.7 & 16.9 & & \\
\hline HSD-16 & 169.4 & 1.9 & 8.3 & 16.2 & 24.6 & 14.5 & C & $\begin{array}{l}\text { V-vial, 3-way } \\
\text { stopcock }\end{array}$ \\
\hline
\end{tabular}

Table 2

Holmium scout dose (HSD): Comparison of different methods of injection

\begin{tabular}{|llllll|}
\hline \multicolumn{5}{c}{ Method of injection } \\
\hline & & A & B & C & p-value \\
\hline Initial activities & V-vial $\left(\mathrm{MBq}^{*}\right)$ & $111.1 \pm 45.3$ & $122.8 \pm 55.9$ & $91.1 \pm 35.2$ & 0.502 \\
\hline No. of microspheres & $($ millions*) & $1.3 \pm 0.6$ & $1.4 \pm 0.6$ & $1.0 \pm 0.4$ & 0.417 \\
\hline Residual activities & Total $\left(\mathrm{MBq}^{\star}\right)$ & $35.3 \pm 17.6$ & $22.8 \pm 16.9$ & $13.7 \pm 6.9$ & 0.037 \\
\cline { 2 - 6 } & Total $\left(\%{ }^{*}\right)$ & $31.2 \pm 9.6$ & $17.7 \pm 6.9$ & $15.0 \pm 6.0$ & 0.005 \\
\hline *values are mean $\pm \mathrm{SD}$ & & & & & \\
\hline
\end{tabular}


Table 3

Therapeutic radioembolizations (RE): Procedure characteristics

\begin{tabular}{|c|c|c|c|c|c|c|c|}
\hline \multirow{2}{*}{$\begin{array}{l}\text { Procedures } \\
\text { (chrono-logical) }\end{array}$} & \multirow{2}{*}{$\begin{array}{l}\text { Prescribed } \\
\text { activities } \\
\text { V-vial } \\
(\mathrm{MBq})\end{array}$} & \multirow{2}{*}{$\begin{array}{l}\begin{array}{l}\text { No. of } \\
\text { micro- } \\
\text { spheres }\end{array} \\
\text { V-vial } \\
\text { (millions) }\end{array}$} & \multicolumn{4}{|c|}{ Residual activities } & \multirow{2}{*}{$\begin{array}{l}\text { Localization of } \\
\text { high activity } \\
\text { accumulations }\end{array}$} \\
\hline & & & $\begin{array}{l}\text { V-vial } \\
(\mathrm{MBq})\end{array}$ & $\begin{array}{l}\text { Delivery } \\
\text { set } \\
(\mathrm{MBq})\end{array}$ & $\begin{array}{l}\text { Total } \\
(\mathrm{MBq})\end{array}$ & $\begin{array}{l}\text { Total } \\
\text { (\%) }\end{array}$ & \\
\hline RE-01 & 3230 & 13.7 & 31.5 & 110.4 & 142.0 & 4.4 & $\begin{array}{l}\text { needle A } \\
\text { connector }\end{array}$ \\
\hline RE-02 & 4544 & 19.6 & 7.7 & 170.9 & 178.6 & 3.9 & $\begin{array}{l}\text { needle A } \\
\text { connector, } \\
\text { microcatheter } \\
\text { connector }\end{array}$ \\
\hline RE-03 & 3347 & 13.8 & 10.3 & 107.3 & 117.6 & 3.5 & $\begin{array}{l}\text { needle A } \\
\text { connector, 3-way } \\
\text { stopcock }\end{array}$ \\
\hline RE-04 & 4627 & 15.1 & 42.8 & 127.2 & 170.0 & 3.7 & $\begin{array}{l}\text { needle A } \\
\text { connector }\end{array}$ \\
\hline RE-05 & 2980 & 10.6 & 41.0 & 134.4 & 175.4 & 5.9 & $\begin{array}{l}\text { needle A } \\
\text { connector, } \\
\text { microcatheter } \\
\text { connector }\end{array}$ \\
\hline RE-06 & 2021 & 7.2 & 28.7 & 55.0 & 83.7 & 4.1 & $\begin{array}{l}\text { needle A } \\
\text { connector }\end{array}$ \\
\hline RE-07 & 3800 & 16.0 & 119.9 & 38.0 & 157.9 & 4.2 & V-vial \\
\hline RE-08 & 2305 & 9.0 & 66.4 & 89.1 & 155.5 & 6.7 & V-vial \\
\hline RE-09 & 993 & 3.9 & 16.5 & 52.2 & 68.7 & 6.9 & $\begin{array}{l}\text { needle A } \\
\text { connector, 3-way } \\
\text { stopcock }\end{array}$ \\
\hline $\mathrm{RE}-10$ & 3254 & 10.7 & 47.7 & 65.6 & 113.3 & 3.5 & $\begin{array}{l}\text { V-vial, 3-way } \\
\text { stopcock }\end{array}$ \\
\hline $\mathrm{RE}-11$ & 2013 & 8.3 & 41.8 & 74.9 & 116.6 & 5.8 & $\begin{array}{l}\text { needle } A \\
\text { connector, V-vial }\end{array}$ \\
\hline $\mathrm{RE}-12$ & 1690 & 6.9 & 22.7 & 56.7 & 79.5 & 4.7 & $\begin{array}{l}\text { needle A } \\
\text { connector }\end{array}$ \\
\hline
\end{tabular}


Table 4

Therapeutic radioembolizations (RE): Activity transfer per injection cycle

\begin{tabular}{|lllll|}
\hline Injection cycle & \multicolumn{4}{l}{$\begin{array}{l}\text { Proportion of injected activity } \\
\text { (\%) }\end{array}$} \\
\hline & Mean & SD & Min. & Max. \\
\hline 1 & 24.0 & 2.0 & 21.1 & 26.9 \\
\hline 2 & 42.2 & 4.8 & 37.3 & 49.8 \\
\hline 3 & 21.4 & 4.9 & 14.4 & 27.7 \\
\hline 4 & 7.4 & 2.3 & 4.4 & 9.9 \\
\hline 5 & 3.0 & 0.6 & 1.8 & 3.7 \\
\hline 6 & 1.3 & 0.1 & 1.2 & 1.5 \\
\hline Flush $(4 \times 5 \mathrm{ml})$ & 0.7 & 0.2 & 0.4 & 0.9 \\
\hline
\end{tabular}

Figures 


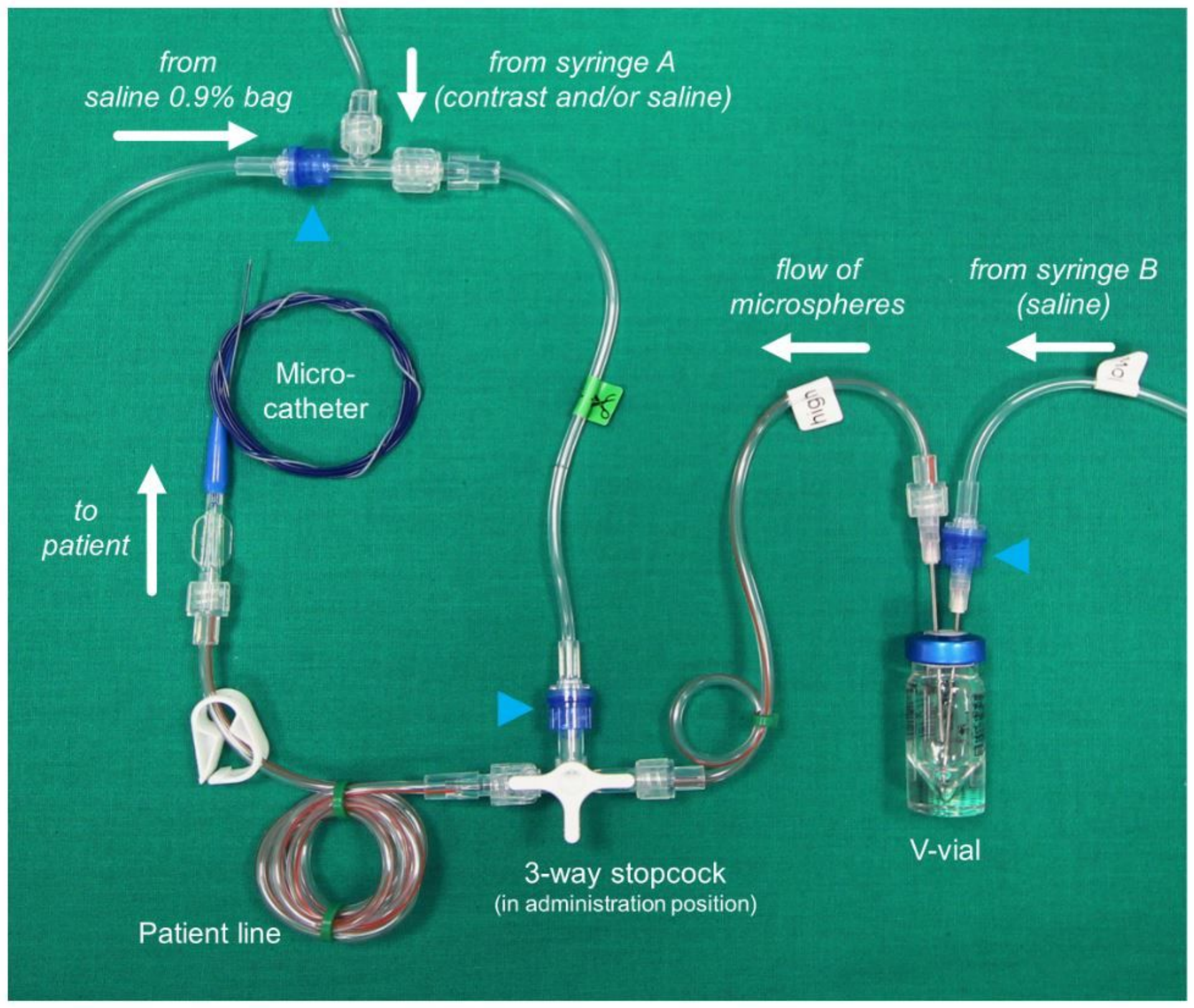

\section{Figure 1}

PLLA microspheres delivery set. Saline solution injected with syringe B flushes the microspheres out of the Vvial, through the 3-way stopcock to the patient. The 5-mL syringes can be refilled from attached saline bags. Blue connectors (arrowheads) are one-way valves. 


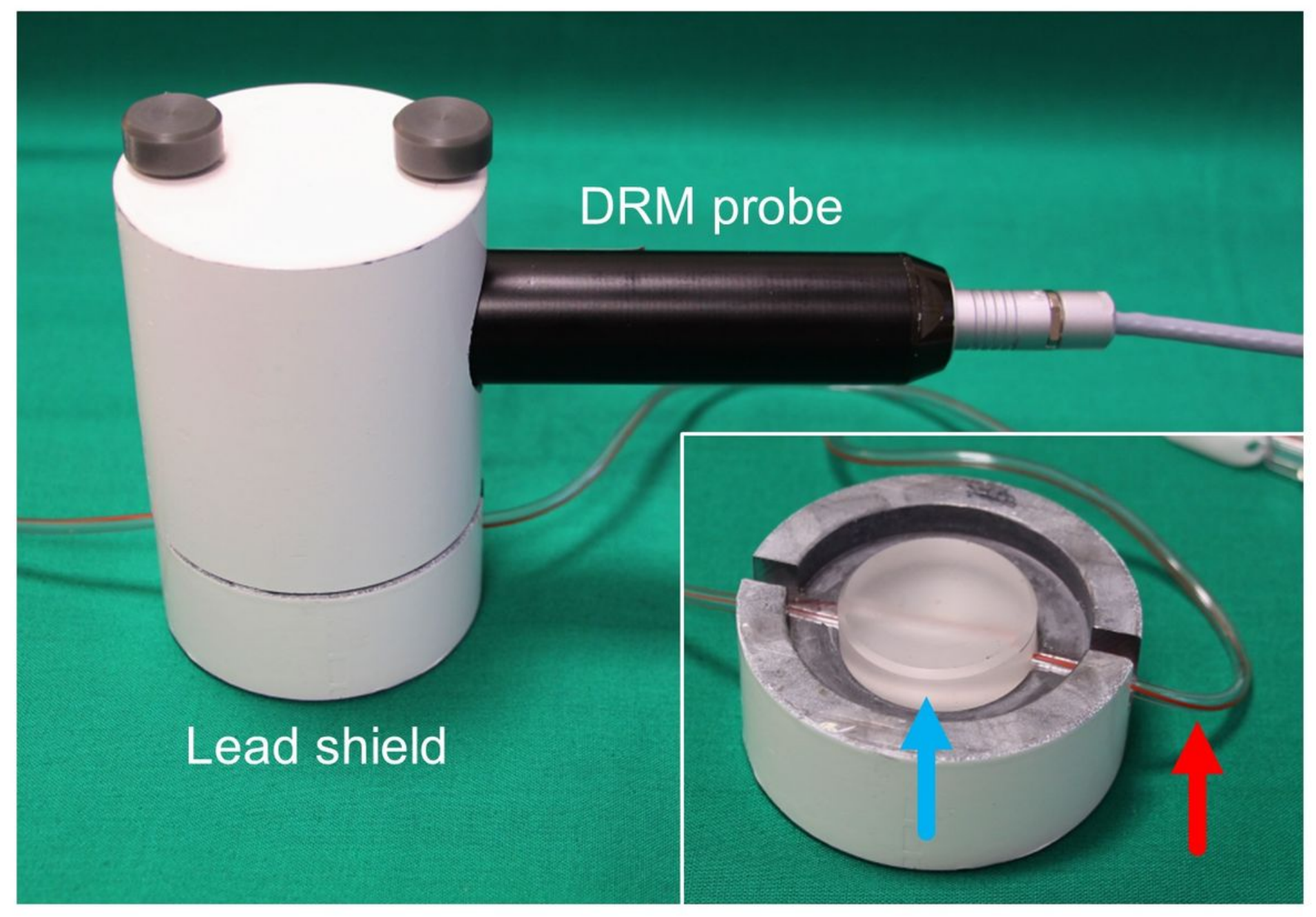

\section{Figure 2}

For measurement of activity flow during procedures, the patient line (red arrow) was placed between acrylic glass wafers (blue arrow) inside a lead shield with a dose rate meter (DRM) probe. 

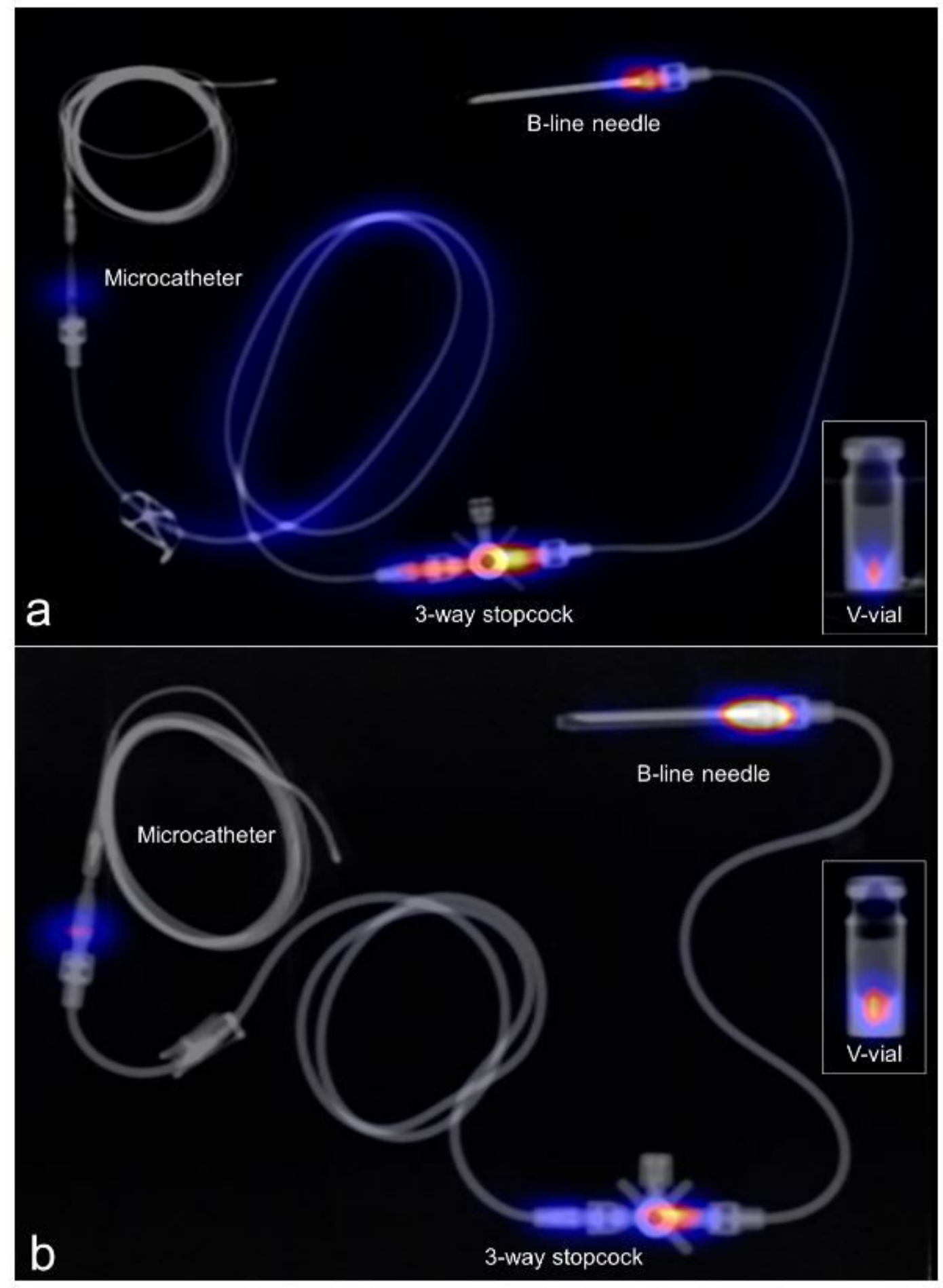

\section{Figure 3}

SPECT/CT images of the delivery set and V-vial after scout dose (a, HSD-07) and therapeutic procedures (b, RE-09) show a similar pattern of residual activity. 

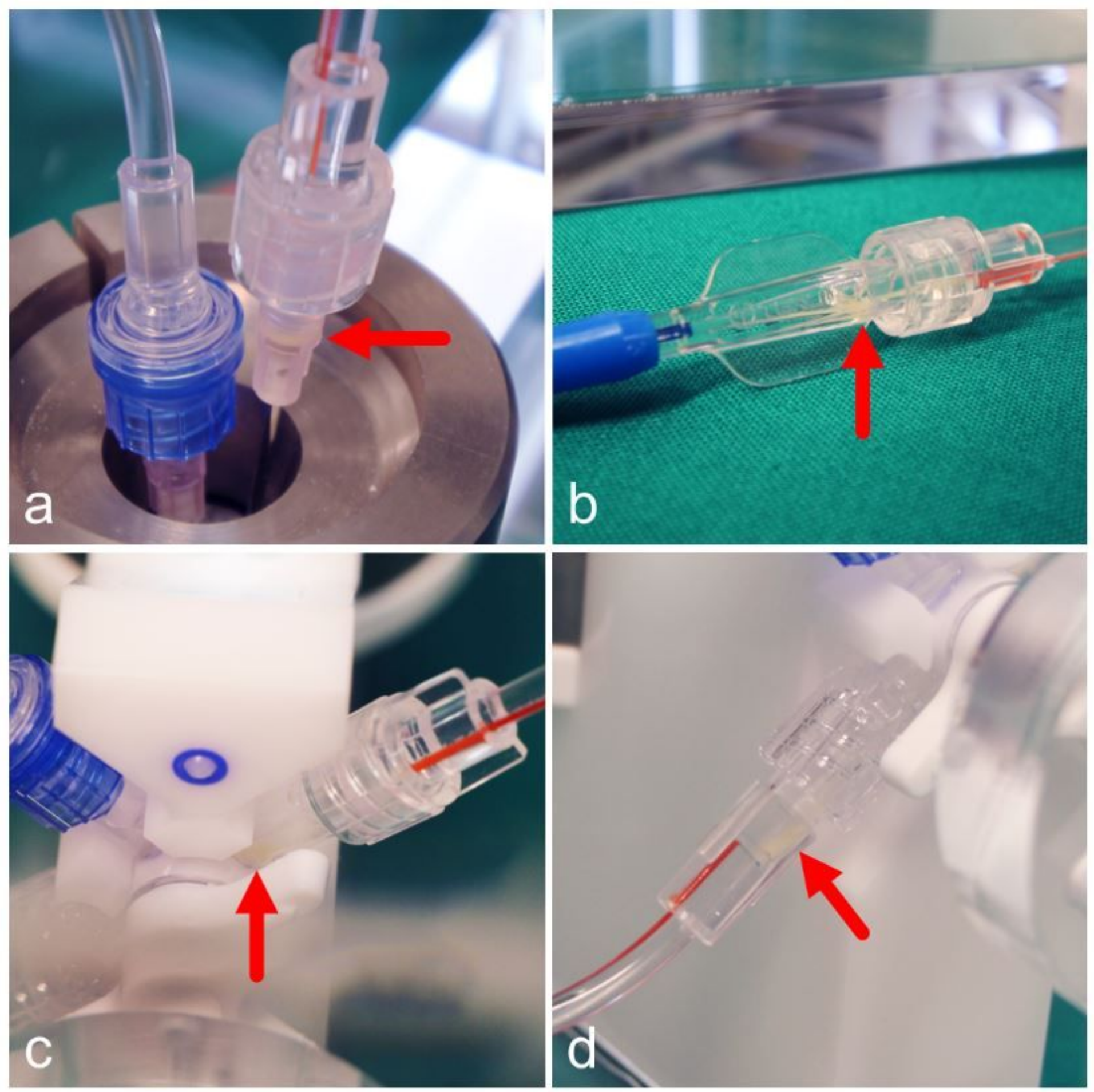

Figure 4

Microsphere accumulations at the outflow needle connector (a), the microcatheter connector (b), the 3-way stopcock (c, junction between inflow and pivoting part) and the proximal end of the patient line (d, red arrows). 


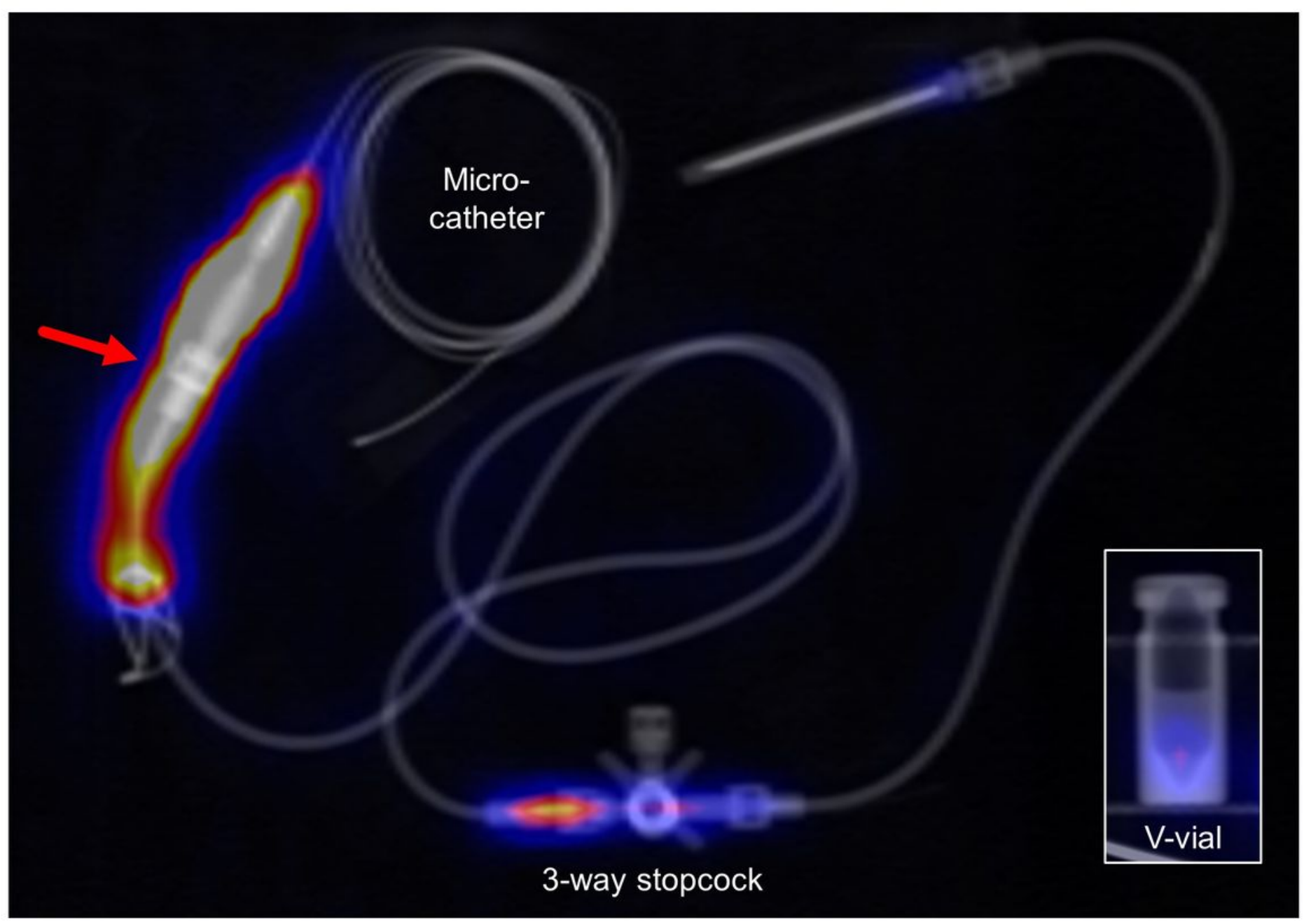

\section{Figure 5}

HSD procedure with the highest residual activity, 44.1\% of $84.9 \mathrm{MBq}$ Ho-166, performed with injection method A (HSD-04). The majority of the residual microspheres is located at the microcatheter connector (arrow). 


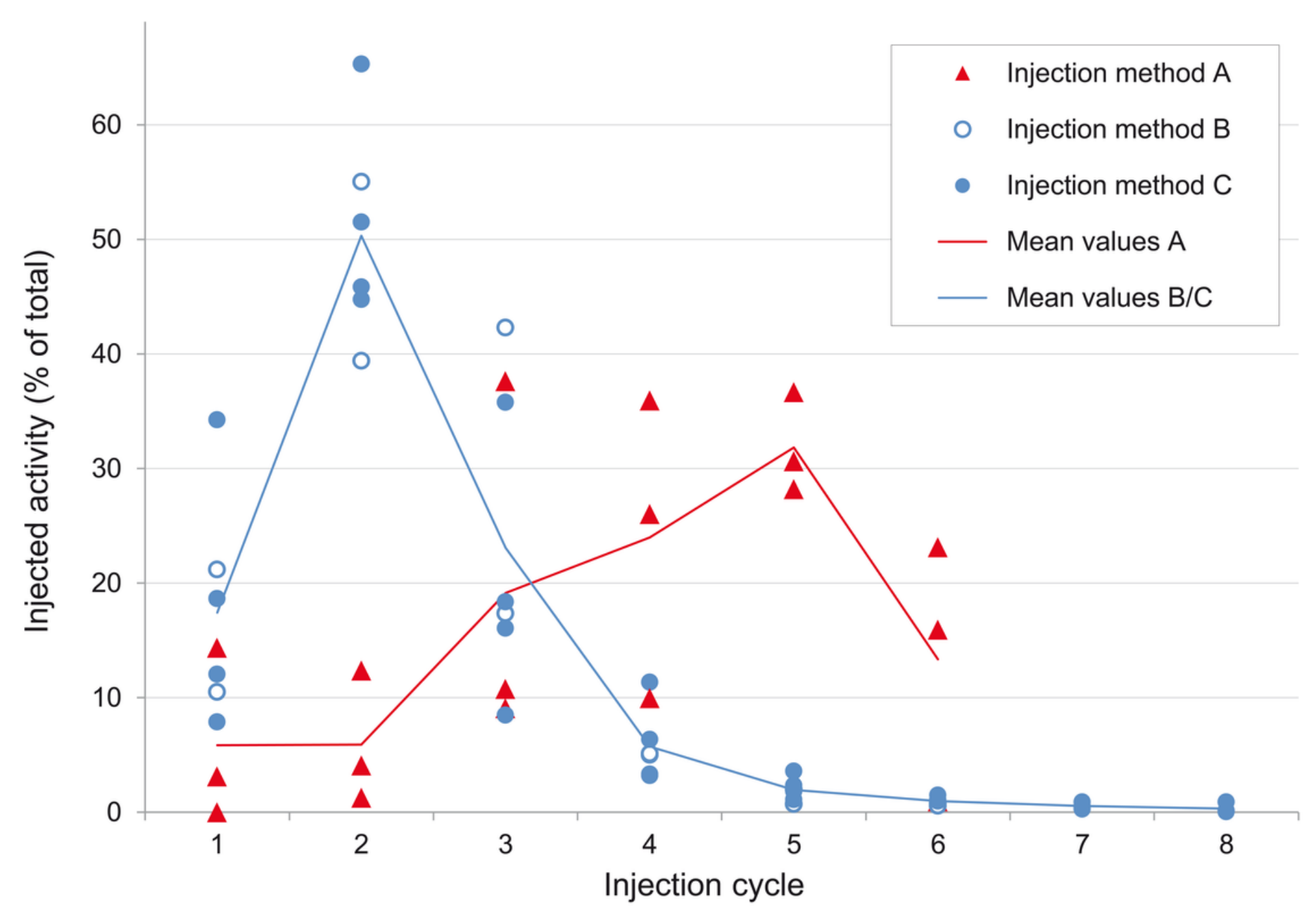

Figure 6

Transfer of prescribed activities during HSD injection cycles. With method A, most microspheres are transferred during the second half of the procedure, with high variability. With methods $B$ and $C$, only differing in the number of flushing cycles, activity transfer is as expected for injection of a suspension with continuous dilution (B/C data were pooled for mean curve calculation). 


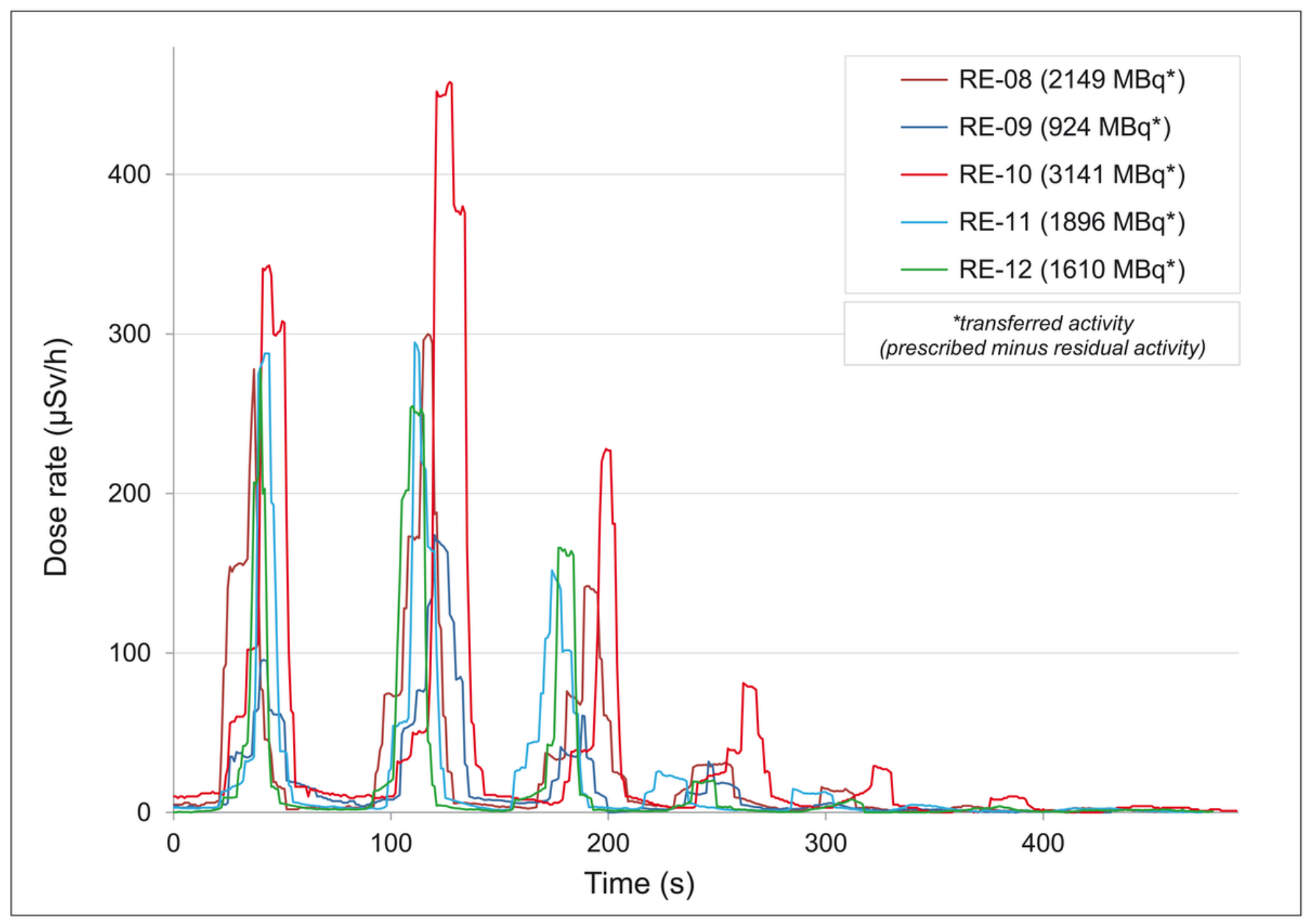

Figure 7

Flow of activity measured by DRM at the patient line during five RE procedures. Most microspheres are transferred during the first and second injection cycles. Less than $1 \%$ of the total activity is transferred during final flushing. Mean procedure duration was 7:47 min +/-0:20 min (range 7:11-8:09 min). 